\title{
Confession, psychology and the shaping of subjectivity through interviews with victims of female-perpetrated sexual violence
}

\section{Sherianne Kramer ${ }^{1,2} \cdot$ Brett Bowman $^{1}$}

Accepted: 3 June 2021 / Published online: 14 June 2021

(c) The Author(s), under exclusive licence to Springer Nature Limited 2021

\begin{abstract}
Female-perpetrated sexual abuse (FSA) is often seen as rare and of little consequence. Confessing to being a victim of FSA is infrequent and often met with incredulity. Identifying as such a victim is thus often a response to an incitement to speak in the mode of confession. Interviews producing the possibility for such confessions were conducted with ten self-identified South African FSA victims and then analysed using a Foucauldian approach. In identifying as victims of FSA the participants drew on psychologised, gendered accounts of damage reflected in trauma, revictimisation, memory loss, the cycle of abuse and deviance. An analysis of these accounts demonstrates how confessional sites, such as the (psychological) interview, anchor victim worthiness in damage so that 'non-normative' victims of violence are able to see themselves in sexual violence discourse as forever compromised subjects whose healing requires rethinking the relationship between gender, sexuality, and violence in contemporary South Africa.
\end{abstract}

Keywords Female-perpetrated sex abuse $\cdot$ Sexual violence $\cdot$ Victimhood Confession · Psychological interview

\section{Introduction}

Gender-based violence (GBV) is currently portrayed as a 'global crisis' (see Miranda 2020) that primarily impacts women. This view has been further endorsed by contemporary trends such as the \#MeToo Movement which aims to disrupt rape culture and concerns about women's safety in the context of the

Sherianne Kramer

Sherianne.kramer@gmail.com

1 School of Human and Community Development, University of the Witwatersrand, Johannesburg, South Africa

2 School of Public Health, University of the Witwatersrand, Johannesburg, South Africa 
COVID-19 Pandemic (Mittal and Singh 2020; Solórzano et al. 2020). While no doubt global in scope, this crisis is even more pronounced in contexts such as South Africa where gender, racial and economic inequalities and traditional patriarchal norms serve as a backdrop to almost daily reports of sexual violence and rape (Seedat et al. 2009; Treves-Kagan et al. 2020).

Sexual violence, one type of GBV, is constructed as distinctively different for men, women, and children. Shaped by gendered and sexuality discourses, sexual violence emerges as an act perpetrated by men on women and children. Thus, constructions of violence imply a hierarchy of vulnerability (Moore 1994) where children are constructed as most vulnerable and women a close second. Child victims are always possible, even where the perpetrator is a woman; however, given the male's position as the least vulnerable to sexual violence in this hierarchy, male victims, particularly those sexually violated by a woman or a child, complicate the logic of this hierarchy of vulnerability. The magnitude of these complications acts as a strong reminder that the 'real' possibility for men to be victims of female-perpetrated sexual abuse (FSA) is always questionable (Kramer 2017). This seems to be the case in South Africa despite the country's legislated reconceptualisation of sexual violence to include men as potential victims and women as potential perpetrators (Minister for Justice and Constitutional Development 2007). While contemporary discourses are certainly less rigid and thus have produced broader conditions of possibility for the subjectification of victimhood, this does not seem to be the case in the more traditional context of South Africa where binarised conceptions of violence continue to imply who can and cannot occupy victimhood by virtue of their gender and racial categories. Victim worthiness and subjectification is thus deeply implicated by the cultural discourses that surround FSA.

Primarily, self-identification as a victim requires victim worthiness rooted in the construction of damage to an inherently valuable life. Exploring the porous edges of the victim worthy subject as an object of human science research (Bowman et al. 2015) is of course entirely political, because it contributes to the everexpanding net of surveillance that produces key actors in the calculus of violence (Kramer 2017). For Foucault (1978), it is precisely because the subject is constituted by and within language and power that exploring 'new' forms of sexual violence will inevitably produce new possibilities for victims and perpetrators by the very logic that drive such projects. Thus, victimhood does not pre-exist language and power but rather it exists as its instrument and effect (Butchart 1997). This study takes discourse and material conditions as they circulate within forms of power as targets for understanding how, under certain historical, social and contextual conditions, a particular category (FSA victims) of victimhood is produced. The aim of this enquiry is thus to identify how the self is constituted through confessional incitements in the context of a study of FSA victimhood in South Africa. In doing so, this paper contributes to the growing interdisciplinary scholarship that critically explores the relationship between subjectivity and culture as a means to understand the intersections of power, ideology and agency (Gill 2008). 


\section{Sex, sexuality and the incitement to speak}

A Foucauldian position views "power as a productive and creative force that fabricates individual and collective human bodies through the microtechniques of the social-medical sciences' (Butchart 1997, p. 102) and other authoritative institutions such as religion, law and the media. Discourses on gender, sexuality and other forms of identity are circulated by these institutions, relayed onto bodies and incorporated into various subjectivities. These interlocking networks of discourses constrain what can and cannot be considered 'victimisation' and undermine the severity and seriousness of the consequences of female sex acts (Muehlenhard and Kimes 1999) which make claims to being a victim of FSA difficult for certain kinds of subjects. Given the FSA victim's tenuous status in currently circulated discourse, opportunities for persons subjected to FSA to take up a victim subject position are significantly constrained. In keeping with Foucault's (1978) account of how modern sexuality has been constituted as a privileged site of insight into self-hood, it is often the technology of the confession as a form of incitement to discourse that prompts the subject to speak about sex and sexuality in the most minute kinds of details that can be continuously dissected to expand the surveillance of human science knowledge (Dominguez-Whitehead et al. 2017). In this way subjects speak sex into the human sciences, and these sciences carve out new possibilities for sexuality, and therefore the 'self' (Kotze and Bowman 2018). However, the reach of this confessional apparatus still rooted in the governance of sexuality has more generally emerged as an important resource in the modern project of self-making (Rose 1999).

\section{Psychology, sexuality, damage and self-making}

For Foucault (1978), against the backdrop of modern regimes of sexuality, one of the primary means of 'self-making' occurs through the process of confession. In the act of confession, the speaker's actions are transformed from illegitimate to legitimate and his 'subjectivity from bad to good, from outside law and truth to inside' (Alcoff and Gray 1993, p. 270). These confessional requirements are so deeply engrained in the structure of modern societies that the confessional context has become a normative and primary means of producing discourses on sex (and self-hood), resulting in the invisibility of the disciplinary obligation to confess. In turn, the role of power in such obligations is invisibilised (Foucault 1978). Structurally, the confession implies that 'truth' is hidden within a subject as an assembly of secrets that must be liberated (Phelan 1990) and the desire for disclosure is constituted as natural (Tell 2007). So, 'the self is not disclosed by confession, it is constituted by confession' (Tell 2007, p. 4) and the confessional context is one of the primary means to the production of 'truth'.

In contemporary secular societies, psychotherapeutic settings have largely replaced the church as the conventional confessional. This is possible because 
the historical constitution of sexual deviancy has implicated the psychotherapeutic model as a therapeutic confessional site that facilitates healing (Pryce 2000). The therapeutic model is a means of producing categories of sexual abuse and constituting sexual abusers and victims as subjects that 'inhabit' subjectivities aligned with violation and abuse. However, this conventional conception of the relationship between therapeutics, trauma and confession is not uncontested. For Cvetkovich (2003), the assumption that speaking about sexual violence may be seamlessly therapeutic is complicated by the fact that ' $[\mathrm{t}]$ he obstacle to retrieving the memory of trauma is not necessarily that it has been repressed but that, due to dissociation, for example, it was never experienced in the first place' (p. 384). This position on the politics of traumatic memory is extended by Levett (1990) who argues against even the residues of psychologisation in Cvetkovich's (1985) position that there are specific 'rules' that apply to confessions that reflect the traumatic or are trauma-related. Individuals that identify as sexually abused expect to be traumatised 'although they may be unclear as to what exactly this 'damage' would involve' (Levett 1990, p. 43). Thus, sex traumas replete with 'discourses of damage' (Levett 1990) circumscribe victimhood as an inevitable outcome of abuse. Addressing this 'damage' requires consistent self-surveillance so that the minutiae of the act and its impact can be disclosed to the expert (most usually construed as a psychotherapist) who can legitimate and corroborate this disclosure. The psychotherapist 'expert' is therefore key to the incitement to discourses on sex and trauma which are arguably the product of intersecting social processes and definitions rather than an outcome of any particular event (Swartz and Levett 1990). However, given that the gender of the aggressor in FSA is largely incompatible with constructions of sexual and violence related trauma, FSA victims tend to be less interpellated by the incitement to discourse (and trauma) in the confessional.

In line with Foucault's understanding of subjectivity, subjects are constituted in discourse through power (Foucault 1978). Thus while an individual is shaped and formed through ongoing processes of subjection, the subject is constantly producing self-hood through various technologies that cluster around self-making as a modern project (Foucault 1985). For Foucault (1985), these technologies of the self are the behaviours and manners in which subjects comply with the ensemble of discursive codes by which they are regulated. Foucault (1985, p. 25) refers to these codes as 'moral orthopaedics', and describes them as 'a set of values and rules of action that are recommended to individuals through the intermediary of various prescriptive agencies such as the family...educational institutions, churches, and so forth'. The inference is that those individuals that do not comply with this 'moral code' are drawing on technologies of the self to practice resistance. This echoes Butler's (1997) contention that performativity is discursively constitutive in either the reproduction of or resistance to such authoritative codes. Thus while the practice of confession could be seen as complying with the incitement to speak under the order of modern sexuality, the content of that confession (i.e. what is spoken) could be viewed as a reflective form of self-making. This intersection of subjectification and self-making means that confessing to being a victim of FSA or performing this kind of victimhood could be understood simultaneously as subjection and resistance. 
In the confessional context of the therapeutic space, sexual abuse is a particularly powerful mode of relaying Foucault's (1985) practices of the self as they do or do not comply with 'moral orthopaedics'. Because sexual abuse is framed as an experience that occurs on the female body, 'the socially produced feminine body is precisely that... of a guilty pre-victim' (Cahill 2000, p. 56). The construction of the female body as sexually penetrable renders the female subject potentially responsible-'she was somewhere she should not have been, moving her body in ways that she should not have, carrying on in a manner so free and easy as to convey an utter abdication of her responsibility of self-protection' (Cahill 2000, p. 56). Richardson and May (1999) augment this line of argument by describing violence as always gendered and victimhood as always mediated through culpability, and so the constituents of violence and abuse are deeply circumscribed by social and historical conditions (Fisher and Cullen 2000; McCartan et al. 2015). These two points, taken together, explain why certain victims are treated as 'deserving victims' (Boonzaier 2014). For example, a woman dressed in a 'provocative' way or a gay victim of homophobic violence (both subjects being threats to the heteronormative social order and perceived as promiscuous) 'are unlikely to be construed as 'innocent' victims' (Richardson and May 1999, p. 310). Studies have demonstrated that homosexual male rape victims are likely to be held more accountable for their sexual victimisations than their heterosexual counterparts and are perceived to experience pleasure in the act of a sexual assault. Both hetero- and homosexual male victims are frequently considered less traumatised than female victims of the same sex crime (Barth et al. 2013; Mitchell et al. 1999). Constructions of rape require the identification of who is and/or is not accountable and deserving in the event and therefore who has the adjunct responsibility to confess (Weiss 2010a), which leads to victims actively seeking opportunities for disclosure (Posel 2005). This implied accountability produces typical feelings of guilt, shame and self-loathing that victims of sexual violence describe. These feelings are based on widely circulated implications that rape defiles and tarnishes a female sexuality and body that is often (although not universally) constructed as sanitised and pure (Weiss 2010a). The construction of rape as an event that occurs on a fragile and penetrable female body is reinforced by biological 'truths' inscribed on the gendered body that imply that while all men may not be rapists, all women are potentially rape victims. This is forcefully evident in the context of South Africa where the exceptionally high incidence of sexual violations against women (Seedat et al. 2009) has resulted in a media, public and professional discursive focus being on female victimhood which in turn has found further support in South African mental health professionals, academics and police workers being unable to fully conceive the likelihood of sexually violent women (Kramer and Bowman 2011). These constructions preclude FSA victims from being produced as 'victim worthy' subjects, in turn limiting disclosure and help-seeking (confessional) opportunities readily available to other victims.

Against this backdrop, claims to FSA victimhood are only recently conceivable within discourses on sex, rape, trauma and damage through the increasing number and broadened scope of confessional contexts that afford the confessor 'victim 
worthiness'. This study demonstrates how confessional sites, such as the (psychological) interview work to root victim worthiness in damage and trauma, thus producing new forms of victimhood as part of the growing science of female-perpetrated sexual violence.

\section{Interview as confession: method}

Once ethics clearance was obtained, a call for participants was circulated through public channels across South Africa including on-air radio recruitment; online blogs, social networks, and in print media (magazines and newspapers). The call for participation referred to sexual coercion or behaviour deemed inappropriate by the Criminal Law (Sexual Offences and Related Matters) Amendment Act (Minister for Justice and Constitutional Development 2007), in requesting participants that had been sexually assaulted, molested or raped by a woman. However, in practice, participant selection was not reducible to this definition and rather responded to self-identified victims' own constructions of sex abuse. The call elicited a group of ten participants, including five men and five women. Interviews with these participants were transcribed and analysed using Parker's $(1992,2004)$ Foucauldian-based approach which aims to demonstrate the way discourses construct objects of knowledge and subjects within frameworks of power. This type of discourse analysis is thus geared for application to interview data containing victims' discursive accounts of their FSA experiences.

The interview context is undoubtedly an instantiation of the confessional apparatus as it is used to draw out 'secret' information to be interpreted and the presence of an 'expert' at the receiving end of this information is key to the incitement to discourse in gauging its 'truth value' (Pryce 2000). Structurally, the data collection component of this study aligns to the confessional context in its design that incites discourse on FSA by inviting participants into the 'confessional mode'. This was emphasised by the use of psychotherapy rooms for the interviews, which positioned the researcher firmly in the field of psychology. Given the traditional ethical procedure that requires informed consent and assurance of confidentiality at the beginning of the research process, all of the participants related their stories, often for the first time, with the understanding that they were confidential. This ethical requirement inadvertently and ironically supported the confessional format and thus the incitement to sex abuse discourse. Given the researcher's position in the discipline of psychology, together with questions directly related to participants' sexualities and sex lives and the context of the interview as an anonymous and confidential space, participants felt not only the desire to speak but also, the obligation to do so. This is in line with Pryce's (2000) suggestion that the incitement to discourse operates at the nexus of the expert (or psychotherapeutic) gaze and the implication that the interview is the standard device to elicit content to be interpreted and decoded. Furthermore, the interview, by virtue of its structure, implies that there is value to 'confessing', especially if there is an expert present. The confessional context is typified by the 'expert' other's interpretation and evaluation of the status, identity, experiences and speech of the confessor. So, although the confession appears to 
empower the victim through providing an opportunity to speak, it is the 'expert' listener who determines the legitimacy and value of the victim's discourse (Alcoff and Gray 1993). However, in this case, because of their self-selection as victims, participants had already identified with the FSA victim subject position. The interview, as an interactional process in which discourses are elicited, exchanged and negotiated, therefore provided a theoretically informed opportunity for performing, clarifying, codifying and elaborating this position (Butler 2004; Weiss 2010b). While these were research interviews, it was the power of their framing by psychology that incited participants to confess, as if the interviews were of a clinical nature. Thus the interview itself formed a key vehicle for the subjectification of the participant (Speer 2002) and therefore the production, transmission and further refinement of FSA victimhood as a category of human science and (self-)knowledge.

\section{The incitement to discourse: victims in waiting}

Discourse has productive power and is thus the field in which the subject emerges (Winnubst 1999). Subjection requires that subjects have access to the language of positional production. For example, child sex abuse (CSA) is often only reported during late adolescence or adulthood. This late reporting is usually coupled with explanations that the gravity of the CSA was only recognised post exposure to particular media platforms, books or conversations (Schaeffer et al. 2011). This incitement to discourse provides subjects the opportunity to construct their experiences as 'victims in waiting'. In much the same way, almost all of the study participants indicated that at the time of their FSA experiences, they did not self-identify as victims. Ella's ${ }^{1}$ comment that 'it took me, you know, years and years and years to make that connection...[to] sexual abuse' points to this process of 'becoming' a victim. It was only after exposure to a particular condition or person, which or whom incited identification as a victim, that participants were able to claim victimhood. For Suzette, this exposure was in the form of her father which surfaced in the interview when she was asked to describe her relationship with her perpetrator (mother):

I was really close to her, um until my dad kind of like explained to me that it was wrong, what she did and then I kind of like started realising, slowly but surely that my dad is right...I started feeling really stupid that I didn't realise like my mom was actually abusing me and being really wrong compared to other mothers and what like the law said.

Suzette further consolidated her victim status through other incitements to speak in detail about the abuse. After disclosure to legal representatives, Suzette was asked to provide a detailed description of her experience, this narrative thus serving to further reify her victimhood:

\footnotetext{
1 Participants' names have been changed to maintain their anonymity.
} 
I had to go into detail, what had happened. I didn't really want to do it. I... before the time I was like begging my dad, please don't let me do this, I don't want to do it and then my dad said 'ya but you have to. Even I don't want you to do it but the court says, says you have to. You don't have that much of a choice in this'.

Of interest is the perceived lack of choice identified by Suzette or, as Foucault (1978, p. 20) puts it, 'the obligation to admit to violations of the laws of sex' and the injunction to do so by providing the most minute of details. This perceived obligation, implied by the presence of legal structures and authorities results in a 'confession' that provides several contouring coordinates for FSA victimhood. The implicit obligation to confess sexual victimisation results in the victim's acceptance of some responsibility for the incident (Posel 2005; Weiss 2010a). Richard described feeling 'shamed' and 'belittled', while Tanaka indicated that he 'felt really bad' and Anna said she was 'vulnerable' and 'ashamed'. Charles reported that he felt 'dirty' and 'worthless' and Heather stated that 'there was just the most profound guilt'. The incitement to discourse afforded participants an opportunity to 'confess' their FSA experiences and in so doing, FSA victimhood was constituted (rather than disclosed). The findings that follow reveal the technologies of incitement that make confession possible. The technologies employed by participants included psychologisation through therapy, the internet and media and all seem to be conditional on access to class capital.

\section{Class conditions for confession}

The technologies employed by participants were accessed in the context of participants' tertiary educations, careers, therapy sessions, and support group networks - all signifiers of class capital. It therefore seems that, at least in the South African context, socioeconomic status is deeply implicated in the subjective experience of victimhood. Contrariwise, the majority of female sexual offenders incarcerated in South African correctional centres are uneducated and are from low-income backgrounds (Kramer 2017). Another interesting difference between the two groups is that these incarcerated offenders are primarily black, while the current study identified mainly white victims ( 80 percent). Additionally, interviews with incarcerated female offenders have demonstrated that they do not perceive themselves as FSA perpetrators (see Kramer 2017), whereas the participants in this study self-identified as FSA victims. It seems that the privilege of 'whiteness' allows for white-identifying subjects to occupy more socially marginalised positions without serious consequence given their advantage and unequal access to power simply by virtue of their position within hegemonic class structures. The findings in this study are therefore particular to FSA victims of a very unrepresentative class and race context in South Africa and work to further demonstrate the limited access most FSA victims have to at least see themselves in, or materially claim victimhood in South Africa. 


\section{Psychologised discourse}

One of the central findings to this study is that access to 'psychotherapeutic' discourse provides an opportunity for subjects to occupy victimhood. On the one hand, this was easily surfaced due to the participants' introduction to the interviewer as a psychological researcher as well as the confessional architecture of the interview context. However, on the other hand, most of this psychotherapeutic discourse appeared to be based on participants' previous exposures to therapy, psychological practices or work in the actual field. It thus seemed that the interview, coupled with the researcher's status, assisted in the reification of discursive contours of the 'suspected' victimhood that preceded it.

Most of the participants claimed that their therapists, counsellors or support groups were central to their self-identifications as FSA victims. Additionally, participants discussed the value of therapy in assisting them to 'deal' with their victimhood:

I also had a very big mental block when it came to it and the psychologist helped me get through that... She says the more people I speak to, um within the future whether it be medically, in terms of more psychologists or just letting friends know is that it would definitely better me as a person (Charles).

The implication by Charles' therapist that he should continuously speak about his FSA experience is a powerful example of the incitement to discourse proper. It also echoes Butler's (2004) argument that identity-making is dependent on a speaker repeatedly and consistently performing a particular discourse, in this case FSA victim discourse. Another example of the way access to the 'psychotherapeutic' incited FSA victimhood includes:

I think because I've shared it before, um, with a psychologist is that...it's a lot easier to speak about. The first time obviously definitely was not easy. Especially when speaking to another female... which I personally in my mind find odd, that I'm able to speak to someone about a female problem. Yet she's a female... and I feel...threatened as such. But knowing that she was a psychologist and has dealt with these problems before is that I haven't seen her as a threat (Charles).

Charles' statement that 'knowing that she was a psychologist and has dealt with these problems before' points to the requirement of an 'expert' listener to validate his FSA experiences as part of the incitement to discourse.

Some of the participants reported that they work in the psychological field and that this has provided them with opportunities for understanding their situations. Richard is a support group leader for male survivors of sexual violence, Thabo is a psychological researcher and Jane is a psychology student. It was evident that this work allowed these three participants additional access to psychotherapeutic discourse that, in turn, further enabled identification with victimhood. As Richard noted, 
I do a lot of therapy online so I give a lot of people- I have a particular uh, empathy for survivors' wives and family. I kind of relate to them quite well because I know how badly I damaged mine, you know?

While psychotherapeutic discourse was one of the key mechanisms and outcomes of incitement, an interesting incitement to the production of FSA victimhood was also the availability of online media forms.

\section{Internet and media}

The current global use of internet and media is a key driver of knowledge production and provides an optimal context for the incitement to peripheral gender discourses. It is also demonstrative of the ways that contemporary media formats have widened incitement opportunities for confessing victimhood (Dominguez-Whitehead et al. 2017). As many of the participants noted, they did not self-identify as FSA victims until they were exposed to material that availed this subject position to them. For example, Ella reported that she did not know how to categorise her FSA experience until she 'got this compulsion to get up on the internet and...look up BDSM-type videos'. Richard also noted,

I pushed the memories of my mother, I didn't remember them at all, I really didn't. Until I went onto the male survivor site, last, last year...I was reading, another guy, and he wrote this story and it was just...mad. It was like...my eyes closed and it was like this little movie playing and it just...all came back to me...I could see myself sitting in the bath, I could see the bathroom, I could smell the soap and the shampoo. Everything. I could feel the warm water. And I sat there reading the story and everything he described in it was exactly how it happened to me. And I never remembered that. And all of a sudden it just came back. It was overwhelming.

Given that FSA victimhood is relatively peripheral in discourses of abuse, seeing 'oneself' as a victim of FSA in language is difficult. However, Richard's identification of the possibilities for his own victimhood is realised in the range of material available online. For the participants, this meant that the internet provided an emerging discourse on curative and supportive options for FSA victims. As Jim indicated,

I think what made things easier for, for victims is the fact that we've now got internet...We've got all these things that can help that person...I mean from my phone. I can go into any site...Like the...MatrixMen ${ }^{2}$...I can do it right here.

\footnotetext{
${ }^{2}$ MatrixMen is a South African website for male survivors of sexual violence (http://www.matrixmen. org).
} 
This self-help discourse enabled by the internet is a key example of the intersection of spoken and material conditions of possibility for the recursive subjectification of victims' positions.

The call for study participants was presented on various media forums and internet sites. Ironically, the call for FSA victims appeared to be one of the very mechanisms that incited the participants to victim discourse. This excerpt provides a powerful example of how the study's incitement to FSA victim discourse further reproduces and reifies this category of victimhood:

I wouldn't say that, for me it wasn't that much of an issue. Um...until I heard the thing with DJ Fresh. ${ }^{3}$ And...it just sparked a lot of memories regarding it...I was listening to what you were saying. And all of a sudden, boom, shit, that happened to me (Jim).

\section{Trauma and damage in victim confessions}

Trauma discourse infers that there must be a victim identity (usually female) and an aggressor identity (usually male). As Jane noted, 'women are seen as the victims, always'. This pattern has generally resulted in the marginalisation of FSA victimhood from widely circulated discourses on trauma and damage, and this is especially so in the context of South African rape and intimate partner violence statistics that perpetually present women and children as victims and men as perpetrators (Seedat et al. 2009). However, this apparent 'marginality' from discourse mirrors Foucault's (1978) critique of the illusion of repression and thus FSA victimhood discourse emerges as a consequence of ostensible silences and prohibitions. Given that the interview context in this study was framed as a 'confessional' site in order to discuss the 'secret' of FSA victimhood, participants actively engaged in a clear production of victimhood and, consequently, damage and trauma. As Jim reported, 'the more you think about it, you didn't get laid, you were raped'. Levett (1992) argues that constructions of trauma resulting from sexual transgressions produce perceptions that the 'victim' is invariably and indelibly damaged. In line with this, participants drew on common victim discourses related to nondisclosure, trauma, revictimisation, cycles of abuse and emotional damage. Interestingly, these are not unlike the victim discourses arising out of male sexual abuse narratives (see Ahrens 2006; Davis 2005; Sturken 1999). However, given the non-normative nature of FSA victimhood, these 'typical' discourses were embedded in complex intersections of sexuality, gender and power that represented points of resistance and the promise of counter-knowledge.

\footnotetext{
${ }^{3}$ Radio interview for the study call for participants.
} 


\section{The secret}

The implication that sexual 'truth' is housed within subjects as secrets to be liberated is intrinsic to the logic of confession and the incitement to discourse. Throughout the interviews, participants constantly spoke of 'the secret' with reference to their FSA experiences:

It was my dirty little secret that I've never said to anybody (Heather).

I had to learn how to...go on with life.... and keep my secret and not let people find out (Jane).

Can you imagine the burden of walking around with a secret that big, that could destroy another family, that could actually eventually come out? (Jim).

These assertions that bind FSA victimhood to secrecy reflect the illusion of the 'repression' or silence of FSA victimhood in discourses on sex. The treatment of their FSA experiences as secrets resulted in the participants opting for nondisclosure to authorities or family. However, 'the secret' is also crucial to the incitement to discourse. Thus, constructing FSA as a secret was also the mechanism through which participants could occupy a victim subject position in the confessional with the 'expert' interviewer.

Nondisclosure is typical in sexual victimisation, rooted in cultural narratives that victims should remain silent (Enns et al. 1995) and is related to shame and the fear of being blamed or not believed. These fears were evident in the participants' reported nondisclosure decisions however, participants also lacked access to a language that could frame their FSA experiences. For example, despite having disclosed her sexual victimisation by a male perpetrator to the legal authorities, Heather failed to report her FSA victimisation because 'it never occurred to $m e$ '. Likewise, Jane indicated that she would have reported the victimisation if her perpetrator was a male because it is 'more socially acceptable'. Given these discursive boundaries, an incitement to discourse could not occur without an 'expert' present that could validate participants' experiences. As Charles offered,

No, I had not reported. The reason being is that... it sounds ridiculous but I don't think that anything would have been done about it at the time... how do you prove it?

Interestingly, both Jim and Richard relayed that they had discussed their sexual victimisation experiences on anonymous support network forums on the internet. Modern technologies, and especially those framed within a psychological context, thus widen the scope for incitement and transfer the requirement of an expert gaze to a peer gaze, so long as this 'peer' is anonymous and offers points of identification. The confessional elements of 'expert' validation, anonymity and experiences of shame were central to the participants' framing of their experiences as secretive, abusive and traumatic. Foucault (1985) argues that subjection is sustained through technologies or practices of the self within historicised forms of moral government. This moral code is an ensemble of regulatory discursive codes or 'moral orthopaedics' that are recommended to subjects via the mechanisms 
of various prescriptive and authoritative institutions. Through the participation in sexual transgressions that violate culturally acceptable and normative sexual moral codes, all of the participants reported feelings of shame, guilt and selfblame. However, they reflexively participated in the constant production of selfhood by attempting to locate themselves within the available mechanisms for sharing, caring and "self-help" online (see Aycock 1995).

\section{Victimhood as destiny}

The frequently cited 'finding' of revictimisation in sexual abuse cases (Gidycz 2011) reflects both the power and durability of the victim subject position once it is occupied. The study participants grounded part of their subjections to this position through the reproduction of classic sex abuse narratives, especially with regards to revictimisation.

For some of the participants, being sexually violated by a woman was accounted for by their previous abuse. As Heather noted, 'I did have some understanding of sexual activity because of previous abuse with neighbours'. Jim explained that, prior to the FSA event with his aunt; his father had always abused him:

I was terrified of my dad. Um...having had all those physical abuse moments from him. I mean can you imagine being tied to a bed. And then being 'donnered $^{4}$ ' is the word I'm going to use. You don't get smacked. You get beaten. With a belt. Much bigger than this (points to his belt). And you're six years old.

However, while Jim explained that 'physical abuse in my house [was an] everyday thing' his FSA experience was perceived as less normative and as something that has the capacity to 'destroy another family... [if it] could actually eventually come out'. This points to the possible differentiation of the sexual and the physical and the construction of sexual abuse as more damaging than physical abuse.

Other participants explained that their FSA experiences 'groomed' them to become victims and as a consequence to be revictimised. For example,

I think by the time the male perpetrators came along, I was kind of already... groomed. And that's the thing that I struggle with. Is that it's almost like my mother groomed me for this evil future that...she opened the door...she started it...she...kind of lowered my standards and, and sort of made me think that it was okay to go with these men...I resent the fact that she started it... she initiated my life as an abuse victim... So it starts with one guy touching you on your back and then you sort of let it happen and the next guy puts his hand down your pants and then you go, 'Well kind of my mom does this, so, you know, what's the problem?' (Richard).

\footnotetext{
${ }^{4}$ Donner is Afrikaans slang meaning to beat up.
} 
When she [my mother] died my father sexually abused me until he died so it sort of all rolled in together then so the whole sexual life is just, you know, a blur of abuse (Heather).

Heather's comments imply that sexual damage is irreparable and permanent, unlike the damage experienced under other kinds of transgressions. Again, this reveals the discursive power of the inevitable trauma that must accompany sexual abuse when compared to its physical, emotional and psychological manifestations. While most of the participants simply used these discourses to relay their victimhood, Jane reflected on its recursivity, again instantiating its power:

Like what does the pattern do? Like I'm always interested to find, like to figure it out because like do people sometimes, if they like get abused once, feel like they need to...go with it again?

Jane's reflections on this 'pattern' is indicative of the way revictimisation is produced within sexual abuse discourses such that it is reified as unshakeable, recalcitrant and forever marking inversions of normality.

\section{Psychic damage}

One of the most cited and controversial findings in the sex abuse literature is that trauma associated with sexual violence often results in repression which is later transformed into recovered memories (see Brewin 2012; Davis and Loftus 2014; DePrince et al. 2012). Despite the controversy surrounding the recovered memory hypothesis, its central position in court cases and media reports on sexual abuse has resulted in its production as a widely circulated psychological discourse. Most of the participants had access to this prominent psychological discourse and so it is unsurprising that their narratives were infused with not only examples of their own memory losses but also their psychological insights into these 'repressed' memories. Interestingly, most of the identified memory losses were concentrated around details of the actual sexual abuse event. Following the incitement to discourse, participants' consequent self-identifications as victims were further validated by the fact that they indeed suffered memory loss:

The abuse, in my childhood, a very difficult thing cause I just...I can't remember...like I have flashbacks...I'm kind of trying to figure out if it actually happened, if the flashbacks are real or if they're just part of my imagination... there's a large part of my childhood that's just kind of blocked out (Richard). It is quite fragmented. Um...I remember as a kid remembering a lot of it. But then kind of suppressing it, obviously. And then as I grew up through my teens, I think I just, it just disappeared, kind of? Although it was there. And then about... a year ago, it came back like quite vividly. In flashbacks. (Jane). I'll put it as crude as possible. She was humping up and down. That's what I can remember...Like you see in the movies when people go blank. That's basically what I've got. I've got a huge gap between 10, 11 years old, up to 
about 13 years old. There's, there's a bit of a gap regarding her. So I don't know if it happened after that. (Jim).

Taking recourse to the problem of memory seems an attempt to validate the abuse. Interestingly, most of these recovered memories or 'flashbacks' surfaced recently in parallel to the emergence of broader global discourses on FSA. For example, Jim indicated that he only recalled his experience when he heard the call for participants for the current study. For Richard, Jane and Ella, their memories arrived in the forms of flashbacks after exposure to similar material in a media format or on the internet. Richard explained that 'I call it my rebirth, when I discovered then that I was a survivor of abuse'. Given that this occurred after exposure to information on FSA, this 'discovery' is less likely due to repression and more likely due to the construction of victimhood within which one could locate such repression. Additionally, in order to be 'victim worthy' one must demonstrate the invariable psychic damage that results from abuse. This psychological 'damage' was especially pronounced in the male victims' discourse which constructed their unwanted physical arousals as body betrayal ('your body betrays you', Jim) and their perceived emasculation and damaged manhood as a result of being unable to resist a female perpetrator (' $I t$ makes me feel like I'm not a real man', Richard) (see Kramer and Bowman 2020). The turn to repression thus appeared to provide the precondition for describing the psychological burden resulting from an abuse that would always disrupt and damage personhood.

\section{Becoming the abuser to become the victim}

The cycle of abuse is another psychological theory that was evoked to construct victim worthiness in the participants' discourses. The assumption that victims become abusers appeared to be rooted in participants' access to psychological frameworks that implied that victimisation (especially sexual) may be linked to later perpetration (see Manchikanti Gómez 2011; Ogloff et al. 2012; Ryan and Lane 2011). So entrenched was this assumption, that participants expressed concern regarding their own sexually violent capacities, this yet another representation of the irredeemable and ever-lasting quality of sexual damage. In line with Schaeffer and colleagues' (2011) argument that male victims are more likely to be treated as potential future perpetrators than female victims, the majority of the participants that occupied this victim-offender potential position were male. Some examples of cycle of violence discourse can be noted in the following extracts:

I don't deserve to have a baby...what if I hurt it? (Thabo).

I can remember changing her nappies and like looking at her fanny and going,

'Don't you dare ever touch that. Don't you dare'. And I'd like clean it. You have to do that as a father, you have to clean it. And then I'd think, 'Stop looking. Stop looking. You're going to hurt her. Don't you dare. You can't do this'...Then I used to bath her as well... and I'd think constantly in my head all the time, you know, 'Don't you forget what you're doing. You know that 
you're a little perv. You know that you're a sicko. Don't touch her. Don't touch her' (Richard).

These turns to the cycle of abuse were expressed in relation to the psychological frameworks that produced them. The gravity of female sexual transgressions is pronounced in the construct having to be underwritten by victim discourses itself:

I think a lot of these women are actually victims anyway. But you also get that horrible label that if you're abused you will go on to be an abuser (Richard). I read about that. And cases of people saying they were paedophiles because they were abused. And it terrified me. Meaning, that does this mean I'm also gonna...I'm still terrified of it today (Thabo).

Participants' access to psychological discourse provided them with the machinery to construct victimhood and to demonstrate their victim worthiness. The cycle of violence forms part of the discourses on sex abuse in general (rather than FSA particularly). However, access to this type of discourse provided the conditions of possibility for FSA victimhood and thereafter provides participants with a set of features with which to construct their victimhood in perpetuity. The ability to occupy FSA victimhood thus depends on its intelligibility among typical victim discourses, albeit that in the case of FSA, the perpetrator must simultaneously share this victim position.

\section{Deviance}

For Foucault (1978), among the proliferation of discourses on sex and sexuality, anomalous or 'deviant' sexuality cases, came to be particularly emphasised in the eighteenth and nineteenth century through a 'perverse implantation' whereby an explosion of discourses on sexuality produced a host of deviations against the normalising sweeps of the child-centred nuclear family. These violations, against the heterosexual couple and thus 'normal' sexuality, produced forms of perversity that were to be annexed and implanted as population wide possibilities by medicine and the law. Foucault (1978) argues that this perverse implantation underlies the obligation to confess to sexuality. Given the confessional context of the interview, participants' constructions of the deviance that must mark them emerged as a means to demonstrate the intractability of the inversion of sexual 'normality' and, so victim worthiness.

One of the strongest claims to victimhood was participants' references to the 'perverse' sexual and gendered consequences of FSA victimisation. All of the participants constructed themselves in an unquestionable relation to perversity and deviance. For example, participants drew on psychological discourse by using their 'psychological insights' to demonstrate that these 'perversions' were linked directly to FSA:

I think...her getting pleasure out of it [the abuse]...I think I dived in pornography because it became - I started to even almost abuse it myself...I also became like quite...I'm not going to say addicted but I also became...the whole 
pornography of it also became my basis in terms of entertainment...I think in terms of sexuality because I got to realise, I got to...I think the, the molestation made me get onto sex way before I was ready (Thabo).

Thabo's comment that his sexually precocious nature as a child was a consequence of his molestation marks a lifelong deviation from 'normality'. Some other examples of the way that FSA was an instrument and outcome of deviance include:

It's made me sexually aggressive...It's a wonder I haven't got AIDS or... because the way I was going on, it was bad. I was literally sexually aggressive (Jim).

I would sleep with anybody who even indicated that they wanted to have sex (Heather).

I spent half my life thinking that I'm such a pervert that I avoid all people (Richard).

Across the participants, discourses concerning nondisclosure, trauma, revictimisation, memory loss, the cycle of abuse and deviance are mobilised through the technologies of the confessional context to frame victimhood. These constructions of abuse are so entrenched that the occupation of a victim position is immediately characterised by these classic victim 'traits' which demonstrate the 'curse' of victimhood by implying that sexual transgressions are intractable and mark self-hood in perpetuity. For male victims this marker of victimhood also had severe consequences for their capacities to find identification within normative constructions of manhood (see Kramer and Bowman 2020).

\section{Conclusion}

The data in this study largely suggest that FSA victimhood is thinkable under certain material and psychologised conditions that are inseparable from talk about 'trauma'. In the context of a confessional interview, performativity (Butler 1990) allowed participants to renegotiate their subjections, perform an alternative discourse and consolidate an FSA victim subject position as a response to an incitement to speak about sex. This context provided participants with the vehicle to produce FSA victimhood in a way that clearly exposed those conditions that make such an object possible. These conditions appear to be rooted in access to particular knowledge such as psychological theory and to technologies such as online material, in turn pointing to a class condition in the context of South Africa. Given the high levels of unemployment and poverty in South Africa (Statistics South Africa 2013) and that the majority of incarcerated female sexual offenders are black and hail from lowincome contexts (Kramer 2017), the implication is that the participant self-selection methodology drawn on by this study is not representative of most South African FSA victims who are unlikely to have access to the discursive resources required to articulate FSA victimhood. South Africa's political landscape is characterised by inequitable social and economic relations, and as demonstrated by the participants in this study, FSA victimhood is not solely dependent on sexuality and gender (de) 
constructions but rather emerges at the intersection of additional complex and competing identity components such as race and class, resulting in a pattern whereby 'trauma' can only be volunteered by a privileged cohort.

The finding that online media resources provide opportunities for incitements also points to the ways that contemporary society offers incitement and validation opportunities for victim subjectification, beyond those theorised by Foucault's confessional model (see Dominguez-Whitehead et al. 2017). Through blogs and forums, the internet, as a 'technology of self' (see Aycock 1995), has transformed the expert gaze so that it includes (and sometimes blurs) both professional and lay experience. Much like the health and parenting communities have seen that constructions of the 'expert' have been rearticulated through the internet (see Bellander and Landqvist 2020; Mungham and Lazard 2011), it seems that FSA victimhood finds validation through online communities of 'peers' with similar experiences.

Despite the salience of trauma and victim discourses, FSA victims remain peripheral to the primary targets of academic, medical, legal and public surveillance. This research therefore both materialises and produces part of the emerging apparatus of discourses and scientific accounts that surface the productive possibilities of FSA victimhood in South Africa. The possibility for these conditions to produce FSA victimhood in this study highlights the politics of psychological knowledge in its constitution of who qualifies for victimhood under current constructions of sexual abuse. Participation in the (psychological) interview process is therefore itself indivisible from the discursive architecture that continues to construct and reify victimhood. In constructing FSA victimhood as the object of research and interviewing self-identified victims, the study's incitement to FSA victim discourse is another $\operatorname{cog}$ in the discursive machinery through which FSA victim subject positions are further reproduced and reified. This potential reification will also certainly impact on a number of other institutional practices. For example, increased FSA victimhood subjectifications could shift policing and the criminal justice system, which currently reduce femininity to passivity and victimisation. This will influence FSA visibility such that there may be a rise in reporting and incarceration rates and an appearance of increased rates of female sexual offending. The human sciences may declare that such sexual violence has always existed and was merely waiting to be discovered and its ever-expanding net of surveillance will be cast wider. While this expansion may still be constrained by a cultural fabric that cannot yet fully conceive of an agentic and sexually transgressive woman, the emergence of FSA victimhood will surely disrupt the gendering of sexual violence and trauma. Revisions to terms such as 'rape', 'sexual abuse' and 'sexual victimisation' 'filter into the culture at large', with the effect of subjects 'realising' the applicability of these new definitions to their experiences (Koss et al. 1994, p. 510). It is thus likely that counterknowledge on FSA victimhood will inform further revisions to understandings of sexual abuse and this in turn will provide conditions for a wider range of subjects to identify as FSA victims. This has both ethical and political implications. The manifestation of increased female sexual offender incarceration rates may result in the construction of an FSA as ominous and damaging, causing widespread moral panic. At least in South Africa this will serve to amplify the recent surge in panic about rape and other forms of sexual violence and in turn drive the increasing scrutiny and 
intensified regulation of female (and other) sex offenders and the social regulation of sexual behaviour. On a more political level, the project of making possible a sexually violent female may serve to rationalise and fuel the continued pathologisation and repression of women's sexual agency. In the context of contemporary narratives on women's sexualities, feminist responses to this research may be concerned with the potentially antifeminist consequences of the reification of FSA. Specifically, the implication is that the production of a sexually violent woman aligns with dominant gender discourses that insinuate the corruptive potential of sexually agentic women. In turn, women become like men (aggressive, sexually potent for example) and, female sexual agency is pathologised and punished. Thus, while the focus on female perpetration does well to provide possibilities for destabilising heteronormative gender binaries, it also runs the risk of driving an antifeminist position. Nonetheless, following Gill's (2008) call for a critically oriented approach to understanding subjecthood, this study creates new possibilities for rethinking gender, sexuality, and violence in contemporary society by demonstrating how subjectivities are produced rather than discovered by the human sciences, and for the ways that FSA victimhood as a special category of subjectivity in South Africa is constituted, articulated or resisted.

\section{References}

Ahrens, C.E. 2006. Being silenced: The impact of negative social reactions on the disclosure of rape. American Journal of Community Psychology 38 (3-4): 31-34.

Alcoff, L., and L. Gray. 1993. Survivor discourse: Transgression or recuperation? Signs: Journal of Women in Culture and Society 18 (2): 260-290.

Aycock, A. 1995. "Technologies of the self:" Foucault and Internet discourse. Journal of ComputerMediated Communication 1 (2): JCMC121.

Barth, J., L. Bermetz, E. Heim, S. Trelle, and T. Tonia. 2013. The current prevalence of child sexual abuse worldwide: A systematic review and meta-analysis. International Journal of Public Health 58 (3): 469-483.

Bellander, T., and M. Landqvist. 2020. Becoming the expert constructing health knowledge in epistemic communities online. Information, Communication \& Society 23 (4): 507-522.

Boonzaier, F., M.N. Lafrance, and S. McKenzie-Mohr. 2014. South African women resisting dominant discourse in narratives of violence. Women Voicing Resistance: Discursive and Narrative Explorations $102-120$.

Bowman, B., G. Stevens, G. Eagle, M. Langa, S. Kramer, P. Kiguwa, and M. Nduna. 2015. The second wave of violence scholarship: South African synergies with a global research agenda. Social Science \& Medicine 146: 243-248.

Brewin, C.R. 2012. A theoretical framework for understanding recovered memory experiences. In True and false recovered memories, 149-173. New York: Springer.

Butchart, A. 1997. Objects without origins: Foucault in South African socio-medical science. South African Journal of Psychology 27 (2): 101-110.

Butler, J. 1990. Gender trouble. New York: Routledge.

Butler, J., 1997. Excitable speech: A politics of the performative.

Butler, J. 2004. Undoing gender. New York: Routledge.

Cahill, A.J. 2000. Foucault, rape, and the construction of the feminine body. Hypatia 15 (1): $43-63$.

Criminal Law Amendment Act 105 of 1997, 1997. Government Gazette 390(18519): 1-48. http://www. info.gov.za/view/DownloadFileAction?id=70763.html.

Cvetkovich, A. 2003. 3 sexual trauma/queer memory: Incest, lesbianism, and therapeutic culture. In $A n$ archive of feelings (pp. 83-117). Duke: Duke University Press. 
Davis, J.E. 2005. Accounts of innocence: Sexual abuse, trauma, and the self. Illinois: University of Chicago Press.

Davis, D. and E. Loftus. 2014. Repressed memories. The Encyclopedia of Clinical Psychology 1-3.

DePrince, A.P., L.S. Brown, R.E. Cheit, J.J. Freyd, S.N. Gold, K. Pezdek, and K. Quina. 2012. Motivated forgetting and misremembering: Perspectives from betrayal trauma theory. In True and false recovered memories, 193-242. New York: Springer.

Dominguez-Whitehead, Y., K.A. Whitehead, and B. Bowman. 2017. Confessing sex in online student communities. Discourse, Context \& Media 20: 20-32.

Enns, C.Z., C.L. McNeilly, J.M. Corkery, and M.S. Gilbert. 1995. The debate about delayed memories of child sexual abuse: A feminist perspective. The Counseling Psychologist 23 (2): 181-279.

Fisher, B.S., and F.T. Cullen. 2000. Measuring the sexual victimization of women: Evolution, current controversies, and future research. Criminal Justice 4: 317-390.

Foucault, M. 1978. The history of sexuality: An introduction. New York: The Penguin Group.

Foucault, M. 1985. The history of sexuality: The use of pleasure.

Gidycz, C.A. 2011. Sexual revictimization revisited: A commentary. Psychology of Women Quarterly 35 (2): 355-361.

Gill, R. 2008. Culture and subjectivity in neoliberal and postfeminist times. Subjectivity 25 (1): $432-445$.

Koss, M.P., L. Heise, and N.F. Russo. 1994. The global health burden of rape. Psychology of Women Quarterly 18 (4): 509-537.

Kotze, E., and B. Bowman. 2018. Coming-out confessions: Negotiating the burden of lesbian identity politics in South Africa. Journal of Homosexuality 65 (1): 1-18.

Kramer, S. 2017. Female-perpetrated sex abuse: Knowledge, power, and the cultural conditions of victimhood. London: Routledge.

Kramer, S., and B. Bowman. 2011. Accounting for the 'invisibility' of the female paedophile: An expertbased perspective from South Africa. Psychology \& Sexuality 2 (3): 244-258.

Kramer, S., and B. Bowman. 2020. The making of male victimhood in South African Female-perpetrated Sexual Abuse. Gender, Place \& Culture, 1-24.

Levett, A. 1990. Childhood sexual abuse and problems in conceptualisation. Agenda 6 (7): 38-47.

Levett, A. 1992. Regimes of truth: A response to Diana Russell. Agenda 8 (12): 67-74.

Manchikanti Gómez, A. 2011. Testing the cycle of violence hypothesis: Child abuse and adolescent dating violence as predictors of intimate partner violence in young adulthood. Youth \& Society 43 (1): 171-192.

McCartan, K.F., H. Kemshall, and J. Tabachnick. 2015. The construction of community understandings of sexual violence: Rethinking public, practitioner and policy discourses. Journal of Sexual Aggression 21 (1): 100-116.

Miranda, M. 2020. Gender-based violence: A global crisis that is handled ineffectually.

Mitchell, D., R. Hirschman, and G.C. Nagayama Hall. 1999. Attributions of victim responsibility, pleasure, and trauma in male rape. Journal of Sex Research 36 (4): 369-373.

Mittal, S., and T. Singh. 2020. Gender-based violence during COVID-19 pandemic: A mini-review. Frontiers in Global Women's Health 1: 4.

Mungham, S. and Lazard, L., 2011. Virtually experts: Exploring constructions of mothers' advice-seeking in online parenting communities. Radical Psychology: A Journal of Psychology, Politics, and Radicalism 9(2).

Moore, H. 1994. The problem of explaining violence in the social sciences. In Sex and violence: Issues in representation and experience, 138-155. London: Routledge.

Muehlenhard, C.L., and L.A. Kimes. 1999. The social construction of violence: The case of sexual and domestic violence. Personality and Social Psychology Review 3 (3): 234-245.

Ogloff, J.R., M.C. Cutajar, E. Mann, P. Mullen, F.T.Y. Wei, H.A.B. Hassan, and T.H. Yih. 2012. Child sexual abuse and subsequent offending and victimisation: A 45 year follow-up study. Trends and Issues in Crime and Criminal Justice 440: 1-6.

Parker, I. 1992. Discourse dynamics: Critical analysis for social and individual psychology. London: Routledge.

Parker, I. 2004. Discourse Analysis. In A companion to qualitative research, 308-312. London: Sage Publications Limited.

Phelan, S., 1990. Foucault and feminism. American Journal of Political Science 421-440.

Posel, D. 2005. Sex, death and the fate of the nation: Reflections on the politicization of sexuality in postapartheid South Africa. Africa 75 (2): 125-153. 
Pryce, A. 2000. Frequent observation: Sexualities, self-surveillance, confession and the construction of the active patient. Nursing Inquiry 7 (2): 103-111.

Rose, N.S. 1999. Governing the soul: The shaping of the private self, vol. 2. London: Free association books.

Richardson, D., and H. May. 1999. Deserving victims?: Sexual status and the social construction of violence. The Sociological Review 47 (2): 308-331.

Ryan, G.T.F., Leversee., and S. Lane. 2011. Juvenile sexual offending: Causes, consequences, and correction, 3rd ed. New Jersey: Wiley.

Schaeffer, P., J.M. Leventhal, and A.G. Asnes. 2011. Children's disclosures of sexual abuse: Learning from direct inquiry. Child Abuse \& Neglect 35 (5): 343-352.

Seedat, M., A. Van Niekerk, R. Jewkes, S. Suffla, and K. Ratele. 2009. Violence and injuries in South Africa: Prioritising an agenda for prevention. The Lancet 374 (9694): 1011-1022.

Solórzano, D.A.N., M.R. Gamez, and O.D. Corcho. 2020. Gender violence on pandemic of COVID-19. International Journal of Health Sciences 4 (2): 10-18.

Speer, S.A. 2002. 'Natural' and 'contrived' data: A sustainable distinction? Discourse Studies 4 (4): 511-525.

Statistics South Africa. 2013. Men, women, and children: Findings of the living conditions survey 2008/2009. Statistics South Africa.

Sturken, M. 1999. Narratives of recovery: Repressed memory as cultural memory. In Acts of memory: Cultural recall in the present, 231-248. Hanover: University Press of New England.

Swartz, L., and A. Levett. 1990. Political oppression and children in South Africa: The social construction of damaging effects. In Political Violence and the Struggle in South Africa, 265-286. London: Palgrave Macmillan.

Tell, D. 2007. Michel foucault and the politics of confession. Paper presented at the annual meeting of the NCA 93rd Annual Convention, Chicago, IL, November 15-18. http://www.allacademic.com/meta/ p187824_index.html.

Treves-Kagan, S., S. Maman, N. Khoza, C. MacPhail, D. Peacock, R. Twine, K. Kahn, S.A. Lippman, and A. Pettifor. 2020. Fostering gender equality and alternatives to violence: Perspectives on a gender-transformative community mobilisation programme in rural South Africa. Culture, Health \& Sexuality 22 (sup1): 127-144.

Weiss, K.G. 2010a. Too ashamed to report: Deconstructing the shame of sexual victimization. Feminist Criminology 5 (3): 286-310.

Weiss, K.G. 2010b. Male sexual victimization: Examining men's experiences of rape and sexual assault. Men and Masculinities 12 (3): 275-298.

Winnubst, S. 1999. Exceeding Hegel and Lacan: Different fields of pleasure within Foucault and Irigaray. Hypatia 14 (1): 13-37.

Publisher's Note Springer Nature remains neutral with regard to jurisdictional claims in published maps and institutional affiliations.

Sherianne Kramer $(\mathrm{PhD})$ is a social science researcher at the School of Public Health at the University of the Witwatersrand and a lecturer for the Amsterdam Council on International Educational Exchange. Her research interests include critical psychology; crime and violence; female and child perpetrated physical and sexual transgression; male victimhood; and gender and sexual identity and performativity. Her book titled, Female-Perpetrated Sex Abuse: Knowledge, Power, and the Cultural Conditions of Victimhood examines the cultural conditions of possibility for FSA victimhood as a means to advance contemporary critical understandings of gender, sexuality and violence.

Brett Bowman (PhD) is a professor in the School of Human and Community Development and Assistant Dean (Humanities Research) at the University of the Witwatersrand, South Africa. His research focuses on the intersections between violence and social asymmetries in low- and middle-income countries. Other interests include the history of the social sciences, race, racism and other related social asymmetries and the historical and contemporary interfaces between the South African sciences and the society in which they are embedded. 